\title{
Faktor-Faktor Yang Berhubungan Dengan Kepatuhan Transfusi Pada Pasien Thalasemia
}

\author{
E. Sri Indiyah Supriyanti ${ }^{1}$, Meri Risma Mariana ${ }^{2}$ \\ ${ }^{1,2}$ Program Studi Ilmu Keperawatan Sekolah Tinggi Ilmu Kesehatan Sint Carolus \\ Jln. Salemba Raya no 41 Jakarta -10440 \\ Telp: (021) 390444. Email : sri.indiyah@yahoo.com
}

\begin{abstract}
Abstrak
Penyakit Thalasemia di Indonesia cenderung meningkat pada tahun 2010 tercatat ada sekitar 5.050 jumlah penduduk yang menderita thalasemia. Penyakit thalasemia memerlukan transfusi seumur hidup dan mempunyai efek samping pengobatan yang cukup serius. Hal tersebut dapat dipengaruhi oleh banyak faktor. Penelitian ini bertujuan untuk mengetahui faktor yang berhubungan dengan kepatuhan transfusi pada pasien thalasemia. Penelitian ini merupakan penelitian deskriptif korelatif dengan pendekatan cross sectional. Tehnik pengambilan sampel yang digunakan total sampling yakni sebanyak 68 responden. Kriteria responden adalah yang sudah melakukan transfusi 3 kali berturut turut. Hasil dianalisis dengan menggunakan uji statistic Chi Square diperoleh tidak ada hubungan yang berkmakna antara tingkat kepatuhan dengan umur $(\mathrm{P}=0,598)$, jenis kelamin $(\mathrm{P}=0,586)$, pekerjaan orang tua $(\mathrm{P}=0,269)$, lama sakit $(\mathrm{P}=0,458)$, penyakit penyerta $(\mathrm{P}=0,635)$, penanggung jawab pembayaran $(\mathrm{P}=0,584)$; serta ada hubungan yang bermakna antara pendidikan dengan kepatuhan transfusi dengan nilai $(\mathrm{P}=0,045)$. Ada hubungan yang bermakna antara pengetahuan orang tua dengan kepatuhan transfusi $(\mathrm{P}=0,009)$. Rekomendasi dari penelitian ini adalah perlunya peningkatan pengetahuan pasien Thalasemia tentang penyakit Thalasemia juga efek samping yang dapat terjadi.
\end{abstract}

Kata kunci : kepatuhan, thalasemia, transfusi

\begin{abstract}
Thalassemia disease in Indonesia tends to increase in the year 2010 noted approximately 5,050 population of thalassemia. Thalassemia disease requires a lifetime of transfusion and has a fairly serious treatment with side efficiency. It can be determined by many factors. Aim of this study was to identify the factors associated with transfusion in thalassemia patients. This research is a correlative descriptive study with a cross-sectional approach. Sampling techniques used in the sample is a total of 68 respondents. The criteria of the respondent are that the transfusion has 3 consecutive attempts. The results were analyzed using the Chi-Square statistic test obtained no meaningful relationship between levels of compliance with age $(P=0,598)$, gender $(P=$ $0,586)$, parental work $(P=0,269)$, long illness $(P=0,458)$, soreness disease $(P=0,635)$, the charge of payment $(P=0,584)$; And there is a meaningful relationship between education and transfusion compliance with value $(P=0,045)$. There is a meaningful relationship between parental knowledge and transfusion obedience $(P=0,009)$. The recommendation of this study is the need to increase the knowledge of thalassemia patients on thalassemia disease.
\end{abstract}

Keywords $\quad:$ compliance, thalassemia, transfusion 


\section{Pendahuluan}

Salah satu penyakit kronis pada anak adalah penyakit thalasemia. Penyakit ini merupakan penyakit kelainan darah yang disebabkan oleh gangguan produksi hemoglobin, sehingga jumlah hemoglobin berkurang. ${ }^{1}$ Prevalensi carrier thalassemia yang paling tinggi di wilayah mediterania adalah Negara Irak dan Saudi Arabia yaitu antara 1155 sedangkan prevalensi carrier di Asia antara lain di Singapura 4\%, Hongkong 2,8\%, Srilangka 2,2\%, dan diikuti oleh India 2,17\%. ${ }^{2}$

Thalasemia diturunkan dari orangtua kepada anaknya melalui gen. Jika kedua orang tua adalah pembawa sifat thalasemia ada kemungkinan $50 \%$ anak pembawa sifat thalasemia (minor) sedangkan 25\% menderita thalasemia mayor dan 25\% lagi anak akan normal. Namun, bila salah satu dari orang tua pembawa sifat, dan satunya lagi normal, maka kemungkinan $50 \%$ anak menjadi pembawa sifat thalasemia, sedangkan $50 \%$ lagi kemungkinan anak akan normal. $^{3}$

Indonesia menjadi salah satu negara dengan angka kejadian thalasemia yang tinggi. Berdasarkan data yang didapat dari Lembaga Eijkman angka kejadian thalasemia alpa di Indonesia sekitar 2,6-11\%, banyak ditemukan di Pulau Sulawesi, pada suku Bugis atau suku Kajang. Thalasemia beta, dengan pembawa sifat terbanyak ditemukan di Pulau Sumatera, dan sekitar hampir $10 \%$ di daerah Palembang. Di Pulau Jawa angka pembawa sifat sebesar $5 \% .^{4}$

Di Pusat Thalasemia anak RSX didapatkan data distribusi pasien thalasemia berjumlah 1.067 jiwa dengan rentang umur kurang dari 2 tahun sampai dengan lebih dari 25 tahun. Penderita perempuan berjumlah 55\% dan laki-laki $45 \%$ adapun distribusi pasien thalasemia berdasarkan jenisnya adalah $50.9 \%$ thalasemia beta, $6 \%$ thalasemia beta/HbE, $2 \%$ thalasemia alfa dan $0.5 \%$ thalasemia lainnya

Hingga saat ini thalasemia belum dapat di sembuhkan cara pengobatan satu-satunya yang dapat dilakukan adalah transfusi darah secara teratur biasanya sekali dalam empat minggu. Pada umumnya anak-anak yang menjalankan transfusi ini tumbuh secara normal. ${ }^{3}$ Perawatan dan pengobatan yang dilakukan dalam jangka panjang dapat menyebabkan kejenuhan bagi penderita dan keluarganya. ${ }^{5}$

Beberapa faktor yang mempengaruhi kepatuhan itu adalah: Usia, jenis kelamin, suku bangsa, pekerjaan, pendidikan, penyakit penyerta, efek samping terapi, penerimaan dan penangkalan terhadap penyakit, agama, budaya, akomodasi, dukungan keluarga, interaksi dengan petugas kesehatan, pengetahuan, status ekonomi orang tua, dan penanggung jawab pembayaran. ${ }^{6}$ Sejalan dengan penelitian Rahayu, Waluyo dan Supardi banyak hal mempengaruhi tingkat kepatuhan diantaranya dukungan keluarga, faktor ekonomi, faktor pendidikan, faktor akomodasi, serta faktor lingkungan dan sosial. ${ }^{7}$ disamping itu seorang anak yang masuk rumah sakit akan mengalami perasaan cemas akibat hospitalisasi. ${ }^{8}$ Kepatuhan para penderita thalasemia terhadap instruksi dokter menyebabkan terkadang pasien thalasemia datang sudah dalam keadaan kadar hemoglobin (Hb) yang sudah sangat rendah $(<5 \mathrm{gr} / \mathrm{dl})$, sesak, dan sangat lemah. Sehingga tujuan dari penelitian ini adalah tentang faktor faktor yang berhubungan dengan kepatuhan pasien thalasemia untuk transfusi. ${ }^{6}$

\section{Metode}

Penelitian ini menggunakan metode kuantitatif dengan disain cross sectional. Populasi dalam penelitian meliputi seluruh pasien thalasemia yang telah melakukan transfusi pada 1 Januari 2013 sampai dengan 31 desember 2013. Adapun jumlah populasi sebanyak 817. Sampel yang digunakan adalah total sampling. Jumlah pasien dalam 1 tahun di pusat Thalasemia RSCM 817:12=68. Jadi jumlah sampel pada penelitian ini 68 orang. Penelitian dilaksanakan pada bulan Agustus s/d Desember 2013 di Pusat Thalasemia Anak RSCM dengan menggunakan data sekunder dan data primer oleh karena itu alat pengumpul data yang di gunakan adalah rekam medik pasien dan kuisioner pada pasien dan keluarga yang melakukan transfusi. Analisis data yang digunakan adalah Chi square (karena membandingkan skala ukur nominal dan ordinal ) dengan derajat $\operatorname{kemaknaan}(\alpha) 5 \%=$ 0,05 . 


\section{Hasil}

Dari peneitian yang telah dilakukan didapatkan hasil yang yang mengenai distribusi dari karekteristik responden yang terdiri dari umu, jenis kelamin, pendidikan, lamanya penyakit, penanggung jawab pembayaran, kepatuhan transfusi, pengetahuan orang tua dan intervensi petugas.

Tabel 1. Distribusi Frekuensi Karakteristik Individu (n=68)

\begin{tabular}{|c|c|c|}
\hline Variabel & Frekuensi & Presentasi \\
\hline \multicolumn{3}{|l|}{ Umur } \\
\hline $0-5$ thn & 19 & $27,9 \%$ \\
\hline $6-12$ thn & 49 & $72,1 \%$ \\
\hline \multicolumn{3}{|l|}{ Jenis Kelamin } \\
\hline Laki-laki & 42 & $61.8 \%$ \\
\hline Perempuan & 26 & $38.2 \%$ \\
\hline \multicolumn{3}{|l|}{$\begin{array}{l}\text { Pendidikan } \\
\end{array}$} \\
\hline Tdk sekolah & 22 & $32,4 \%$ \\
\hline SD & 41 & $60,3 \%$ \\
\hline SMP & 5 & $7,4 \%$ \\
\hline \multicolumn{3}{|l|}{ Pekerjaan } \\
\hline Bekerja & 47 & $69.1 \%$ \\
\hline Tidak bekerja & 21 & $30.9 \%$ \\
\hline \multicolumn{3}{|l|}{ Lamanya Penyakit } \\
\hline $1-5$ tahun & 27 & $39.7 \%$ \\
\hline$\geq 6$ tahun & 41 & $60,3 \%$ \\
\hline \multicolumn{3}{|l|}{ Penyakit Penyerta } \\
\hline Ada & 49 & $72,1 \%$ \\
\hline Tidak ada & 19 & $27.9 \%$ \\
\hline \multicolumn{3}{|c|}{ Penanggung jawab pembayaran } \\
\hline Ada & 65 & 95.6 \\
\hline Tidak ada & 3 & 4.4 \\
\hline \multicolumn{3}{|l|}{ Kepatuhan transfusi } \\
\hline Patuh & 11 & $16.2 \%$ \\
\hline Tidak Patuh & 57 & $83.8 \%$ \\
\hline \multicolumn{3}{|l|}{ Pengetahuan orang tua } \\
\hline Baik & 46 & 67.6 \\
\hline Buruk & 22 & 32.4 \\
\hline \multicolumn{3}{|l|}{ Interaksi petugas } \\
\hline Melakukan & 40 & 58.8 \\
\hline Tidak Melakukan & 28 & 41.2 \\
\hline Total & 68 & 100 \\
\hline
\end{tabular}

Pada tabel 1 di atas dapat di lihat bahwa mayoritas responden berusia 6-12 tahun sebanyak 49 responden $(72,1 \%)$. Responden mayoritas berjenis kelamin kali-laki sebanyak 42 responden $(61,8 \%)$. Tingkat pendidikan responden SD sebanyak 41 responden $(60,3 \%)$. Mayoritas orang tua responden bekerja sebanyak $47(69,1 \%)$. Lamanya responden menderita penyakit thalasemia $\geq 6$ tahun sebanyak 41 responden (60,3\%). Mayoritas responden memiliki penyakit penyerta sebanyak 49 responden $(72,1 \%)$.
Mayoritas responden memiliki penanggung jawab pembayaran sebanyak 65 responden $(95,6 \%)$. Responden mayoritas tidak patuh dalam melakukan tranfusi sebanyak 57 responden $(83,8 \%)$. Pengetahuan orang tua mayoritas baik sebanyak 46 responden $(67,6 \%)$. Mayoritas petugas melaklukan interkasi terhadap responden sebnyak $40(58,8)$.

Hasil bivariate dalam penelitian ini ditampilkan pada table 2 yaitu terkait hubungan berbagai karakteristik individu dengan kepatuhan transfusi 
Tabel 2. Hubungan Karakteristik Individu Berhubungan Dengan Kepatuhan Transfusi ( $n=68)$

\begin{tabular}{|c|c|c|c|c|c|c|c|}
\hline \multirow[t]{3}{*}{ Variabel } & \multicolumn{6}{|c|}{ Tingkat Kepatuhan } & \multirow[t]{3}{*}{ Nilai $\mathrm{p}$} \\
\hline & \multicolumn{2}{|c|}{ Patuh } & \multicolumn{2}{|c|}{ Tidak patuh } & \multicolumn{2}{|c|}{ Total } & \\
\hline & $\mathbf{N}$ & $\%$ & $\mathbf{N}$ & $\%$ & $\mathbf{N}$ & $\%$ & \\
\hline \multicolumn{8}{|l|}{ Umur } \\
\hline $0-5$ thn & 4 & 21,1 & 15 & 78,9 & 19 & 100 & 0,598 \\
\hline $6-12$ thn & 7 & 14,3 & 42 & 85,7 & 49 & 100 & \\
\hline \multicolumn{8}{|l|}{ Jenis kelamin } \\
\hline Laki-laki & 7 & 16,7 & 35 & 83,3 & 42 & 100 & 0,586 \\
\hline Perempuan & 4 & 15,4 & 22 & 84,6 & 26 & 100 & \\
\hline \multicolumn{8}{|l|}{ Pendidikan } \\
\hline Belum sekolah & 6 & 27,3 & 16 & 72,7 & 22 & 100 & 0,045 \\
\hline $\mathrm{SD}$ & 3 & 7,3 & 38 & 92,7 & 41 & 100 & \\
\hline SMP & 2 & 40,2 & 3 & 60 & 5 & 100 & \\
\hline \multicolumn{8}{|l|}{ Pekerjaan } \\
\hline Bekerja & 9 & 19,1 & 38 & 80,9 & 47 & 100 & 0,269 \\
\hline Tidak bekerja & 2 & 9,5 & 19 & 90,5 & 21 & 100 & \\
\hline \multicolumn{8}{|l|}{ Lamanya sakit } \\
\hline $1-5$ tahun & 5 & 18,5 & 22 & 81,5 & 27 & 100 & 0.458 \\
\hline$\geq 6$ tahun & 6 & 14,6 & 35 & 85,4 & 41 & 100 & \\
\hline \multicolumn{8}{|l|}{ Penyakit penyerta } \\
\hline Ada & 8 & 16,3 & 41 & 83,7 & 49 & 100 & 0.635 \\
\hline Tidak ada & 3 & 15,8 & 16 & 84,2 & 19 & 100 & \\
\hline \multicolumn{8}{|c|}{ Penanggungjawab pembayaran } \\
\hline Ada & 11 & 16,9 & 54 & 83,1 & 65 & 100 & 0.584 \\
\hline Tidak ada & 0 & 0 & 3 & 100 & 3 & 100 & \\
\hline \multicolumn{8}{|l|}{ Pengetahuan orang tua } \\
\hline Baik & 11 & 23,9 & 35 & 76,1 & 22 & 100 & 0.009 \\
\hline Buruk & 0 & 0 & 22 & 100 & 46 & 100 & \\
\hline \multicolumn{8}{|c|}{ Interaksi petugas kesehatan } \\
\hline Melakukan & 4 & 10 & 36 & 90 & 40 & 100 & 0.094 \\
\hline Tidak melakukan & 7 & 25 & 21 & 75 & 28 & 100 & \\
\hline
\end{tabular}

Dari tabel 2 di atas dapat di lihat bahwa responden yang berumur 6-12 tahun dan patuh sebanyak 7 orang $(14.3 \%)$. Hasil uji statistic chi square di diperoleh nilai $\mathrm{p}=0,598>0.05$, maka Ha di tolak sehingga dapat disimpulkan bahwa tidak ada hubungan antara umur dengan kepatuhan transfusi pada anak dengan thalasemia. Responden yang berjenis kelamin laki-laki dan patuh sebanyak 7 orang (16.7\%). Dari uji statistik chi square diketahui tidak ada hubungan yang bermakna antara jenis kelamin dengan tingkat kepatuhan transfusi pada pasien thalasemia dengan nilai $\mathrm{P}=0,586(\mathrm{P}>0,005)$, yang berarti $\mathrm{Ha}$ ditolak. Responden yang belum bersekolah dan patuh sebanyak 6 orang (27.3\%). Hasil uji statistik chi square menyatakan ada hubungan yang bermakna antara pendidikan dengan tingkat kepatuhan transfusi pada pasien thalasemia dengan
$\mathrm{P}=0,045$ (nilai $\mathrm{p}<0.05$ ) yang berarti hipotesa Ha diterima. Responden memiliki oarng tua yang bekerja dan patuh melakukan transfuse sebanyak 9 orang $(19.1 \%)$.

Dari uji statistik chi- square diketahui tidak ada hubungan yang bermakna antara pekerjaan dengan tingkat kepatuhan transfusi pada pasien thalasemia dengan $\mathrm{P}=0,269$ (nilai $\mathrm{p}>0.05$ ), yang berarti hipotesa adalah $\mathrm{Ha}$ ditolak. Responden mengalami sakit $\geq 6$ tahun dan patuh sebanyak 6 orang (14.6\%). Hasil uji statistik chi square diketahui tidak ada hubungan yang bermakna antara lamanya sakit dengan tingkat kepatuhan transfusi pada pasien thalasemia dengan $\mathrm{P}=0,458$ (nilai $\mathrm{p}>0.05$ ). Responden memiliki penyakit penyerta dan patuh sebanyak 8 oarng (16.3\%), hasil uji uji statistik chi square diketahui tidak ada 
hubungan antara penyakit penyerta dengan tingkat kepatuhan transfusi pada pasien thalasemia dengan $\mathrm{P}=0,418$ (nilai $\mathrm{P}>0.05$ ) dengan kesimpulan $\mathrm{Ha}$ ditolak. Responden yang memiliki penanggung jawab pembayaran dan patuh sebanyak 11 orang (16.9\%), hasil uji statistik chi square menyatakan tidak ada hubungan yang bermakna antara penanggung jawab pembayaran dengan tingkat kepatuhan transfusi pada pasien thalasemia dengan $\mathrm{P}=1.000$ (nilai $\mathrm{p}>0.05$ ). Responden yang memiliki orang tua berpengetahuan baik dan patu sebanyak 11 orang (23.9\%), dari uji statistik chi square diketahui ada hubungan yang bermakna antara pengetahuan orang tua dengan tingkat kepatuhan transfusi pada pasien thalasemia dengan $\mathrm{P}=0,009$ (nilai $\mathrm{p}>0.05$ ). Responden yang tidak merasakan bahwa petugas melakukan interaksi dan patuh sebanyak 7 orang (25\%). Hasil uji statistic chi square di diperoleh nilai $\mathrm{p}=0,094>0.05$, maka Ha di tolak sehingga dapat disimpulkan bahwa tidak ada hubungan antara interaksi petugas dengan kepatuhan transfusi pada anak dengan thalasemia.

\section{Pembahasan}

Hasil analisis univariat menggambarkan distribusi frekuensi dari variabel-variabel penelitian yaitu umur, jenis kelamin, pendidikan, pekerjaan orang tua, lamanya penyakit, penyakit penyerta, penanggung jawab pembayaran, kepatuhan transfusi, interaksi petugas, dan pengetahuan orang tua. Distribusi umur menunjukkan bahwa 49 responden $(72,1 \%)$ melakukan transfusi di pusat thalasemia berumur 6-12 tahun. Thalasemia mayor dapat didiagnosa pada janin dan neonatus manifestasinya muncul pada bayi umur 6-12 bulan bayi tampak pucat, iritabilitas, anoreksia, demam dan sering mengalami pembesaran abdomen.

Distribusi berdasarkan jenis kelamin didapatkan 42 responden $(61.8 \%)$ yang melakukan transfusi di pusat thalasemia di RS $\mathrm{X}$ berjenis kelamin laki-laki. Penyakit thalasemia adalah penyakit keturunan yang diturunkan orangtuanya. Penyakit ini dapat di turunkan pada anak laki - laki atau perempuan dalam perbandingan yang sama. Setiap jenis kelamin sama sama berkemungkinan mentransmisikan keadaan tersebut baik kepada keturunan laki - laki maupun perempuan.

Pekerjaan orang tua menunjukkan bahwa orang- tua anak yang melakukan transfusi 47 orang $(69.1 \%)$ adalah bekerja. Biaya pengobatan untuk pasien thalasemia sangat tinggi selama satu tahun diperkirakan sebesar tiga ratus juta rupiah oleh karena itu pendapatan orang tua sangat berperan dalam mendukung program pengobatan pada pasien thalassemia. Distribusi frekuensi berdasarkan lamanya penyakit menunjukan jumlah responden yang terbesar berdasarkan lamanya sakit sebanyak 41 orang $(60,3 \%)$ adalah $6-10$ tahun. Penyakit thalasemia adalah penyakit kronik yang diderita pasien seumur hidup. Semakin patuh pasien thalasemia untuk transfusi angka harapan hidupnya semakim tinggi.

Jumlah responden yang mempunyai penyakit penyerta adalah 49 orang $(72,1 \%)$. Komplikasi yang ada pada pasien thalasemia adalah hepatomegali, kardiomegali, hipersplenomegali. Dari kuisioner yang di dapat pada pasien Thalasemia yang melakukan transfusi di Pusat thalasemia RS X, jumlah terbesar adalah hipersplenomegali yang terjadi karena penumpuk zat besi di organ limpa.

Jumlah responden yang memiliki penanggung jawab pembayaran sebesar 95,6\%. Besarnya biaya yang dikeluarkan untuk pengobatan thalasemia membuat orang tua kesulitan dalam menjalani program pengobatan. Upaya yang diberikan oleh pemerintah untuk memberikan kemudahan dalam pembiayaan salah satunya adalah JAMPELTHAS, jaminan yang khusus diberikan pada pasien thalasemia.

Sebanyak $83,8 \%$ responden tidak patuh transfusi sehingga datang dengan kadar haemoglobin yang rendah $(<8 \mathrm{gr} / \mathrm{dL})$. Hal ini berdampak pada pertumbuhannya oksigenasi ke otak sehingga terjadi penurunan kemampuan intelegensi. Faktor yang dianggap berperan dalam kecepatan pertumbuhan anak thalasemia adalah keteraturan atau kepatuhan transfusi. Sebesar 67,6\% orang tua responden mempunyai pengetahuan yang baik. Pengetahuan yang kurang optimal meliputi thalasemia adalah penyakit menahun dan pasien thalasemia bisa mengalami gangguan pertumbuhan sehingga pasien terlihat lebih kecil dari teman sebaya.

Sebesar $58,8 \%$ responden merasakan interaksi petugas kesehatan. Hasil analisis pernyataan menunjukkan bahwa sebesar $2.9 \%$ perawat mengingatkan kembali untuk datang transfusi. hal ini memang jarang dilakukan petugas kesehatan mungkin disebabkan pasien yang datang adalah pasien yang sudah sering mendapatkan transfusi jadi mereka berpikir tanpa di ingatkan mereka sudah datang sendiri. 


\section{Hubungan antara umur dengan tingkat kepatuhan transfusi}

Pada uji statistic chi square di ketahui tidak ada hubungan yang bermakna antara umur dengan tingkat kepatuhan $\mathrm{p}=0.598$ (nilai $\mathrm{P}>0.05$ ). Tidak adanya hubungan antara umur dengan kepatuhan pada penelitian ini disebabkan karena umur responden pada penelitian ini masih sangat muda sehingga mereka belum menyadari penting nya transfusi bagi dirinya oleh karena itu peranan orang tua masih sangat besar dengan kata lain kepatuhan mereka untuk menjalani transfusi sangat tergantung dengan orang dewasa disekitarnya antara lain orang tua.

Hasil penelitian ini berbeda dengan penelitian yang dilakukan oleh Budiman di RS.Dr. M Jamil Padang, yang mengatakan adanya hubungan yang bermakna antara umur dan kepatuhan dengan nilai $\mathrm{P}=0.027 \quad(\mathrm{p}<0.05)$. Rata rata umur pasien yang lebih tua lebih banyak yang patuh di banding yang tidak patuh. Hasil penelitian ini sejalan dengan pendapat Anggraeni (2009) menyimpulkan tidak ada hubungan yang bermakna antara umur dengan kepatuhan dengan nilai $\mathrm{P}=0,261(\mathrm{P}<0,05){ }^{9}$

\section{Hubungan antara jenis kelamin dengan tingkat kepatuhan transfusi}

Dari uji statistik chi square diketahui tidak ada hubungan yang bermakna antara jenis kelamin dengan tingkat kepatuhan transfusi pada pasien thalasemia dengan nilai $\mathrm{P}=0,586$ ( $\mathrm{P}>0,005)$, yang berarti Ha ditolak.

Tidak adanya hubungan antara jenis kelamin dengan kepatuhan transfusi pada penelitian ini di sebabkan karena Penyakit ini dapat di turunkan pada anak laki - laki atau perempuan dalam perbandingan yang sama. Sehingga jenis kelamin tidak terlalu berpengaruh terhadap kepatuhan transfusi.

Hasil penelitian ini berbeda dengan pendapat dari seorang ahli yang mengatakan bahwa jenis kelamin termasuk faktor yang mempengaruhi kepatuhan.. Hal ini disebabkan anak perempuan mempunyai sifat tidak ingin menjadi beban orang lain, penurut dan takut terhadap hukuman sehingga lebih mudah untuk diberi pengertian tentang manfaat program pengobatan. ${ }^{6}$

Hubungan antara pendidikan dengan tingkat kepatuhan transfusi
Terdapat hubungan yang bermakna antara pendidikan dengan tingkat kepatuhan transfusi pada pasien thalasemia dengan $\mathrm{P}=0,045$ (nilai $\mathrm{p}<0.05$ ) yang berarti hipotesa Ha diterima.

Pendidikan adalah suatu proses pertumbuhan, perkembangan atau perubahan kearah lebih dewasa lebih baik atau lebih matang pada diri individu, kelompok atau masyarakat. Semakin tinggi pendidikan seseorang maka semakin terbuka terhadap informasi sebaliknya jika pendidikan rendah maka akan menghambat perkembangan terhadap informasi. ${ }^{10}$

Adanya hubungan yang bermakna antara pendidikan dan kepatuhan disebabkan karena pendidikan berbanding lurus dengan pengetahuan dan akan diikuti dengan kepatuhan yang baik. Seseorang yang mempunyai pendidikan yang tinggi lebih mengerti saat di berikan informasi dan tentunya merespon informasi tersebut. Pendidikan adalah proses dalam rangkaian mempengaruhi. Makin tinggi pendidikan makin mudah menerima informasi kesehatan. ${ }^{11}$ Sebaliknya orang yang berpendidikan rendah sulit menerima informasi sehingga sulit membuat mereka patuh pada program transfusi. Pada penelitian ini responden yang berpendidikan SMP lebih patuh karena mereka sudah lebih mengerti arti transfusi buat mereka. Semakin mereka patuh maka tubuh mereka akan semakin sehat sehingga mereka bisa beraktifitas seperti teman sebaya mereka. Bagi remaja penyakit dapat mengganggu kemandirian sehingga mereka tidak ingin jatuh dalam keadaan sakit atau lemah. Hubungan yang semakin akrab dengan teman-teman sehingga mereka tidak mau kehilangan waktu bersama teman untuk itu mereka patuh terhadap transfusi agar selalu sehat. Usia remaja juga sudah mulai menyadari kalau mereka tidak patuh transfusi akan berpengaruh kepada citra diri mereka warna kulit menjadi kelabu dan bentuk rahang akan maju kedepan tentunya hal ini mempengaruhi body image mereka, sehingga mereka sangat patuh terhadap transfusi.

\section{Hubungan antara pekerjaan orang tua dengan tingkat kepatuhan transfusi}

Dari uji statistik chi- square diketahui tidak ada hubungan yang bermakna antara pekerjaan dengan tingkat kepatuhan transfusi pada pasien thalasemia dengan $\mathrm{P}=0,269$ (nilai $\mathrm{p}>0.05$ ), yang berarti hipotesa adalah $\mathrm{Ha}$ ditolak. Hasil penelitian ini sesuai dengan 
penelitian Wulandari yang menyimpulkan tidak ada hubungan yang bermakna antara pekerjaan dengan kepatuhan dengan nilai $\mathrm{P}=0.782 .^{12}$

Menurut peneliti kepatuhan pada transfusi lebih tinggi pada orang tua yang bekerja karena orang tua yang bekerja pasti mempunyai penghasilan yang dapat sudah pasti sangat dibutuhkan pada program pengobatan. Besarnya biaya pengobatan pada pasien thalasemia membuat orangtua harus berupaya keras agar mempunyai dan yang cukup untuk itu mereka harus bekerja untuk mendapatkan uang. Bila orangtua tidak bekerja tentunya tidak ada penghasilan yang bisa digunakan untuk mendukung program therapi. Saat ini untuk program transfusi pemerintah sudah memberi kemudahan dengan membebaskan biaya transfusi. Sementara untuk biaya transportasi ke rumah sakit dan biaya makan menjadi tanggungan orangtua yang tentunya tidak sedikit terutama bagi pasien yang tinggal di luar Jakarta. Sehingga tidak jarang mereka menunda transfusi sampai ada uang untuk berangkat ke rumah sakit, yang mengakibatkan mereka datang sudah dengan kadar haemoglobin yang rendah. Jika mereka punya penghasilan tentunya hal ini bisa dihindari.

\section{Hubungan antara lamanya sakit dengan kepatuhan transfusi}

Dari uji statistik chi square diketahui tidak ada hubungan yang bermakna antara lamanya sakit dengan tingkat kepatuhan transfusi pada pasien thalasemia dengan $\mathrm{P}=0,458$ (nilai $\mathrm{p}>0.05$ ). Hal ini sejalan dengan penelitian fatmawati yang menyimpulkan tidak ada hubungan antara durasi penggunaan obat dengan kepatuhan pengobatan dengan nilai $p$ value $=0,375$ dan $\mathrm{OR}=1,572 \cdot{ }^{13}$ Penelitian ini ini tidak sejalan dengan penelitian yang dilakukan oleh Syamsiah yang menyimpulkan adanya hubungan yang bermakna antara lamanya sakit dengan kepatuhan dengan nilai $\mathrm{P}=0,01$ semakin lama seseorang mengidap suatu penyakit semakin tidak patuh terhadap program terapi hal ini mungkin disebabkan oleh adanya rasa bosan terhadap terapi. ${ }^{14}$

Menurut peneliti kepatuhan yang tinggi pada responden yang mengidap penyakit 1- 5 tahun dikarenakan mereka merasa dengan transfusi keadaan mereka lebih baik dan belum ada rasa bosan. Keluargapun masih sangat mensupport mereka, sehingga mereka tidak merasa sendiri. Disamping itu komplikasi pasca pengobatanpun belum ada atau masih sedikit sehingga membuat mereka tetap semangat. Berbeda halnya dengan mereka yang menderita lebih dari 5 tahun mungkin sudah ada komplikasi yang membuat semangat mereka turun dan merasa tidak ada gunanya patuh terhadap transfusi karena penyakit tak kunjung sembuh. Disinilah pentingnya kita sebagai petugas kesehatan memberikan pendidikan kesehatan tentang Thalasemia dan memberikan dukungan baik kepada pasien maupun keluarganya. Keluarga perlu dipersiapkan untuk mendampingi pasien karena penyakit ini sampai saat ini belum ada penyembuhannya. Disarankan agar pasien ikut dalam perkumpulan Thalasemia sehingga mereka dapat berbagi pengalaman atau saling mendukung sesama penderita Thalasemia demikian juga dengan sesama keluarga Thalasemia agar saling menguatkan.

\section{Hubungan antara penyakit penyerta dengan kepatuhan transfusi}

Dari uji statistik chi square diketahui tidak ada hubungan antara penyakit penyerta dengan tingkat kepatuhan transfusi pada pasien thalasemia dengan $\mathrm{P}=0,418$ (nilai $\mathrm{P}>0.05)$ dengan kesimpulan Ha ditolak. Hasil penelitian ini sejalan dengan penelitian Budiman yang menyatakan tidak ada hubungan antara penyakit penyerta dengan kepatuhan transfusi dengan nilai $\mathrm{P}=0.633 .{ }^{5}$

Efek samping dari pengobatan menimbulkan masalah kesehatan yang lain sehingga sangat berpengaruh terhadap kepatuhan, semakin tidak menyenangkan efek samping yang timbul semakin tidak patuh pasien berobat. Hasil penelitian didapatkan hubungan yang bermakna antara ada tidaknya efek samping dengan kepatuhan berobat pasien yang diterapi tamoxifen $(\mathrm{p}<0,05)$. Hasil penelitian ini tidak sesuai dengan penelitian yang dilakukan Budiman dimana didapatkan pasien yang berhenti terapi tamoxifen karena efek samping obat. ${ }^{9}$ Hal ini disebabkan perbedaan populasi yang diwakili dan perbedaan jumlah sampel.

Adanya penyakit penyerta membuat status kesehatan semakin buruk baik dari segi fisik maupun mental. Pada pasien Thalasemia yang memiliki penyakit penyerta hiperpslenisme akan mengalami pembesaran pada daerah abdomen yang tentunya dapat mengurangi aktifitas. Mereka akan datang untuk transfusi bila sudah terlihat pucat atau mengalami kelemahan tanpa memikirkan kadar haemoglobin yang mungkin sudah $<8 \mathrm{gr} / \mathrm{dl}$. 
Pegobatan transfusi yang dilakukan seumur hidup sudah membuat jenuh ditambah dengan penyakit lain tentu membuat semangat mereka turun tentunya hal ini berpengaruh kepada kepatuhan mereka untuk transfusi.

\section{Hubungan antara penanggung jawab pembayaran dengan kepatuhan transfusi}

Tidak ada hubungan yang bermakna antara penanggung jawab pembayaran dengan tingkat kepatuhan transfusi pada pasien thalasemia dengan $\mathrm{P}=1.000$ (nilai $\mathrm{p}>0.05$ ). Hal ini tidak sejalan dengan penelitian Budiman yang menyatakan adanya hubungan bermakna antara penanggung jawab pembayaran dengan kepatuhan dengan nilai $\mathrm{P}=0.026$ yang menyatakan dengan adanya penanggung jawab pembayaran didapatkan kemudahan dalam segi pembiayaan. ${ }^{9}$

Kepatuhan pada pasien yang mempunyai penanggung jawab pembayaran, tinggi. Karena mereka tidak di bebani lagi oleh biaya pengobatan. Pemerintah sudah memfasilitasi dengan pemberian Jampelthas, akan tetapi pada kenyataannya walaupun sudah mempunyai jaminan mereka masih saja tidak patuh. Yang mereka butuhkan bukan hanya untuk biaya transfusi saja, transportasi dan biaya makan juga harus mereka pikirkan. Dari wawancara dengan responden saat pengisian kuisioner tidak jarang mereka mengeluhkan hal ini.

\section{Hubungan antara pengetahuan orang tua dengan kepatuhan transfusi}

Dari uji statistik chi square diketahui ada hubungan yang bermakna antara pengetahuan orang tua dengan tingkat kepatuhan transfusi pada pasien thalasemia dengan $\mathrm{P}=0,009$ (nilai $\mathrm{p}>0.05)$. Hasil penelitian ini sejalan dengan Hendini di Puskesmas Karang-anyar Godang rejo yang menyimpulkan adanya hubungan antara pengetahuan orang tua dengan kepatuhan nilai $\mathrm{P}=0.002$ menyatakan bahwa jika tingkat pengetahuannya tinggi maka tingkat kepatuhannya juga tinggi. ${ }^{15}$ Pendapat ini juga didukung oleh teori yang mengatakan pengetahuan merupakan hasil tahu dan ini terjadi setelah orang melakukan pengindraan terhadap suatu obyek tertentu, dari pengalaman dan penelitian terbukti bahwa perilaku yang didasari oleh pengetahuan akan lebih langgeng dari pada perilaku yang tidak didasari oleh pengetahuan. ${ }^{10}$

Semakin tinggi tingkat pengetahuan, semakin baik pula penderita melaksanakan pengobatan. ${ }^{16}$ Pengetahuan orang tua yang baik akan sejalan dengan kepatuhannya terhadap transfusi, ketidak patuhan transfusi lebih tinggi pada pengetahuan orang tua yang buruk karena orang tua yang buruk tidak mengerti seberapa penting nya transfusi bagi pasien thalasemia. Proses pembelajaran dimaksudkan untuk memberikan pengetahuan pada penderita sehingga terjadi perubahan proses informasi, pengambilan keputusan dan emosi yang pada akhirnya terjadi proses kontrol cognator dalam otak agar melakukan mekanisme belajar dan adaptasi. ${ }^{17}$

\section{Hubungan antara interaksi petugas kesehatan dengan tingkat kepatuhan transfusi}

Hasil uji statistic chi square di diperoleh nilai $\mathrm{p}=0,094>0.05$, maka $\mathrm{Ha}$ di tolak sehingga dapat disimpulkan bahwa tidak ada hubungan antara interaksi petugas dengan kepatuhan transfusi pada anak dengan thalasemia.

Hasil penelitian ini berbeda dengan hasil penelitian yang dilakukan oleh Budiman di RS. Dr.M.Jamil. Padang yang menyatakan adanya hubungan bermakna antara interaksi petugas kesehatan dengan kepatuhan presentasi responden yang patuh lebih tinggipada pasien yang mendapat pelayanan interaksi petugas kesehatan yang baik dengan nilai $\mathrm{p}=0.003 .{ }^{9}$

Penelitian ini di dukung oleh teori Brunner and Suddarth yang mengatakan meningkatkan interaksi profesional kesehatan dengan klien adalah suatu hal penting untuk memberikan umpan balik pada klien setelah memperoleh infomasi. ${ }^{6}$ Suatu penjelasan penyebab penyakit dan bagaimana pengobatan dapat meningkatkan kepatuhan, semakin baik pelayanan yang diberikan tenaga kesehatan, semakin teratur pula penderita melakukan kunjungan pengobatan. Pendapat ini sejalan dengan Niven dalam Bruner dan Suddarth yang mengatakan kualitas interaksi antara profesional kesehatan dan pasien merupakan bagian yang penting dalam menentukan derajat kepatuhan. ${ }^{6}$

Menurut peneliti walaupun responden tidak mendapat interaksi yang baik dari petugas kesehatan angka kepatuhannya tetap tinggi. Hal ini menunjukan bahwa pasien sangat tergantung dengan transfusi tanpa memandang apakah petugas kesehatannya baik dalam memberikan asuhan keperawatan. Dukungan profesional kesehatan sangat diperlukan untuk meningkatkan kepatuhan 
contoh yang paling sederhana adalah tehnik komunikasi.

\section{Kesimpulan}

Tidak ada hubungan antara kepatuhan transfusi dengan umur, jenis kelamin, pekerjaan orang tua, lamanya sakit, penyakit penyerta, penanggung jawab pembayaran, interaksi petugas kesehatan pada pasien Thalasemia di Pusat Thalasemia RSX. Ada hubungan antara kepatuhan transfusi dengan pendidikan, pengetahuan pada pasienThalasemia di Pusat Thalasemia RSX.

\section{Saran}

Pengetahuan responden tentang Thalasemia, efek samping transfusi dan komplikasinya masih sangat rendah. Oleh karena itu, perlu adanya peningkatan pengetahuan pasien dan orang tua tentang hal itu. Baik berupa penyuluhan langsung yang dapat diberikan petugas secara berkelompok ataupun secara pribadi saat memberikan asuhan keperawatan. Televisi yang ada di ruang Thalasemia dapat dimanfaatkan sebagai media informasi tentang penyakit Thalasemia. Perawat menghadirkan dirinya secara utuh dan ini sudah bertentangan dengan prinsip caring "Being there". Oleh karena itu, perlu adanya pelatihan tentang caring untuk para petugas kesehatan juga perlu adanya petugas yang memantau pasien agar pasien dan keluarga dapat mematuhi jadwal transfuse. Perlunya ruangan khusus untuk konseling karena pasien dengan penyakit Thalasemia mempunyai permasalahan yang kompleks. Oleh karena itu, perlu difasilitasi dengan ruangan khusus untuk mereka mengungkapkan permasalahannya.

\section{Daftar Pustaka}

1. Rund \& Rahmilewitsz. Medical \& psicososial aspet of chronics ilness and disability. USA: Ascend learning company; 2012.

2. Oktaviani, Bella. Mekanisme Koping Keluarga Dalam Merawat Anak dengan Thalasemia Mayor usia 6 - 12 tahun di POPTI Kota Bandung, 2017

3. Pediatri, Sari. Thalasemia dan Permasalahannya di Indonesia. Ilmu Kesehatan Anak Fakultas Kedokteran Universitas Indonesia. Vol. 5 No. 1. doi.org/10.14238/sp5.1.2003.2-3 diakses tanggal 9 Juli 2018; 2016.

4. Grentia. Ikatan Dokter Anak Indonesia (Mengenal Thalasemia). Jakarta, 2016. www.idai.or.id diakses pada tanggal 08 juni 2018

5. Leifer. Introduction to Maternity \& Pediatric Nursing: Elsevier Saunders; 2011.

6. Brunner \& Suddarth. Buku ajar keperawatan medikal bedah. Edisi 8, volume 2. Jakarta: EGC; 2013.

7. Rahayu, Y., Waluyo, E.M.J., \& Supardi. Dukungan keluarga dalam kepatuhan terapi pada pasien thalassemia di rumah Sakit Umum daerah Kebupaten Ciamis Tahun 2015. Mutiara Media, vol 16, no 2: 52-56. Juli 2016

8. Purnama, Agus. "Penerapan Atraumatic Care dengan Medical Play terhadap Respon Kecemasan Anak Usia Prasekolah yang mengalami Hospitalisasi di Ruang Rawat Inap Anak." Jurnal Ilmiah Ilmu Keperawatan Indonesia 8.04 2018: 516-521.

9. Budiman, A, Khambri, D. Bachtiar, H. Faktor Faktor yang mempengaruhi kepatuhan berobat pasien yang diterapi dengan Tamoxifen setelah operasi kanker payudara. Jurnal Unand, vol 2. No 1; 2012. http://jurnal.fk.unand.ac.id

10. Notoatmodjo, S. Promosi kesehatan dan ilmu perilaku. Jakarta: Rineka Cipta; 2007.

11. Mubarak, W.I, dkk. Ilmu keperawatan komunitas. Jakarta: Salemba Medika; 2009.

12. Wulandari, Retno. Hubungan status pekerjaan, tingkat pengetahuan, kepatuhan ibu pada budaya, dan keterpaparan penyuluhan gizi terhadap kegagalan pemberian asi eksklusif. http://www.fkm.undip.ac.id

13. Fatmawati, Sellia Andani. Faktor-faktor yang berpengaruh terhadap kepatuhan minum obat pasien diabetes mellitus tipe 2 di RSUD dr. Moewardi periode oktober 2016 - maret 2017. Skripsi tidak dipublikasikan; 2017.

14. Syamsiah, Nita. Faktor-faktor yang berhubungan dengan kepatuhan pasien CKD yang menjalani hemodialisa di RSPAU Dr Esnawan Antariksa Halim Perdana Kusuma Jakarta. Tesis tidak dipublikasikan; 2011.

15. Handayani, D. Hubungan dukungan keluarga dengan kepatuhan lansia dalam mengikuti posyandu lansia di Desa Krajan Kecamatan Waru Kabupaten Sukoharj; 2011.

16. Azwar, Saifuddin. 2007. Sikap manusia, teori dan pengukurannya. Yogyakarta: Pustaka Pelajar, ;2007.

17. Nursalam. Konsep dan Penerapan Metodologi Penelitian Ilmu Keperawatan : Jakarta: Salemba Medika; 2008. 